University of Wollongong

Research Online

Faculty of Social Sciences - Papers (Archive) Faculty of Arts, Social Sciences \& Humanities

$1-1-2018$

Developmental trajectories of competency attainment amongst clinical psychology trainees across field placements

\author{
Frank P. Deane \\ University of Wollongong, fdeane@uow.edu.au \\ Craig J. Gonsalvez \\ Western Sydney University, craigg@uow.edu.au \\ Caroline Joyce \\ Western Sydney University \\ Eileen Britt \\ University of Canterbury
}

Follow this and additional works at: https://ro.uow.edu.au/sspapers

Part of the Education Commons, and the Social and Behavioral Sciences Commons

Research Online is the open access institutional repository for the University of Wollongong. For further information contact the UOW Library: research-pubs@uow.edu.au 


\title{
Developmental trajectories of competency attainment amongst clinical psychology trainees across field placements
}

\author{
Abstract \\ 2018 Wiley Periodicals, Inc. Objective: This research aimed to describe the developmental trajectories of \\ clinical psychology trainees across competency domains over multiple placements. Method: Competency \\ reviews of 252 trainees were completed at mid-placement and end-placement for up to four consecutive \\ placements by 143 field supervisors. Competency was measured across multiple domains using the \\ Clinical Psychology Practicum Competencies Rating Scale. Results: There was an overall ascending \\ stepped pattern occurring across all competency domains from early to late placements. The starting \\ point of competency ratings varied across domains with the largest discrepancy between Response to \\ supervision (highest) and Intervention competencies (lowest). There were significant increases from mid- \\ placement to end-placement for all competencies within each of the four placements. There were few \\ significant decreases in competency between different placements and these were largely restricted to \\ the transition from placement one to placement two. Conclusions: This research has the potential to be \\ used as a benchmark to indicate expected levels of competency attainment for trainees across their \\ training, allowing for early identification of difficulties and more targeted remediation plans.

\section{Disciplines} \\ Education | Social and Behavioral Sciences

\section{Publication Details} \\ Deane, F., Gonsalvez, C., Joyce, C. \& Britt, E. (2018). Developmental trajectories of competency attainment \\ amongst clinical psychology trainees across field placements. Journal of Clinical Psychology, 74 (9), \\ 1641-1652.
}


Developmental trajectories of competency attainment amongst clinical psychology trainees across field placements

Frank P. Deane

School of Psychology and Illawarra Institute for Mental Health, University of Wollongong

Craig Gonsalvez and Caroline Joyce

School of Social Sciences and Psychology. Western Sydney University

Eileen Britt

Department of Psychology, University of Canterbury

Author Note

Correspondence concerning this article should be addressed to Professor Frank Deane, Illawarra Institute for Mental Health, Building 22, Northfields Avenue, University of Wollongong, Wollongong, NSW 2522. Email: fdeane@uow.edu.au Phone: +61 242214523 Fax: +61 242215585

Funding for this project has been provided by the Australian Government Office for Learning and Teaching. We would also like to thank Mark Donovan, Russell Blackman, Roslyn Knight, Yasmina Nasstasia, Alice Shires, and Kathryn Nicholson Perry for collaborating with us on this project.

Short title: Developmental trajectories of competency

Key words: competency, development, training, placement, practicum 


\begin{abstract}
Objective: This research aimed to describe the developmental trajectories of clinical psychology trainees across competency domains over multiple placements.

Method: Competency reviews of 252 trainees were completed at mid- and endplacement for up to 4 consecutive placements by 143 field supervisors. Competency was measured across multiple domains using the Clinical Psychology Practicum Competencies Rating Scale.

Results: There was an overall ascending stepped pattern occurring across all competency domains from early to late placements. The starting point of competency ratings varied across domains with the largest discrepancy between Response to supervision (highest) and Intervention competencies (lowest). There were significant increases from mid- to end-placement for all competencies within each of the four placements. There were few significant decreases in competency between different placements and these were largely restricted to the transition from placement one to placement two.

Conclusions: This research has the potential to be used as a benchmark to indicate expected levels of competency attainment for trainees across their training, allowing for early identification of difficulties and more targeted remediation plans.
\end{abstract}




\section{Introduction}

The past decade has seen an increasing focus on assessment of psychology trainee competency across broad practice domains (Roth \& Pilling, 2008; Smith, Kleun, \& Hutschemaekers, 2007). The assessment of students’ competency has become an integral part of professional psychology training programs and is a practice widely adopted in the training of health service psychologists. Currently, accreditation standards both nationally and internationally ensure that assessment of professional psychology training includes components of coursework, research, and practical experience (American Psychological Association, Commission of Accreditation, 2015; Australian Psychology Accreditation Council, 2010; Kenkel \& Peterson, 2009). Training programs require the student to acquire theoretical knowledge, practical skills and demonstrate appropriate professional attitudes and values to become competent as a practitioner. Recently attention has focused on how to define, classify, and quantify the competencies necessary for a trainee psychologist to be ready to practice (e.g., Fouad et al, 2009; Rodolfa et al., 2005). Further, the focus on competencies has informed and inspired the development of newer models for clinical supervision (Falender \& Shafranske, 2004).

Field placements within psychology are an important component of any health service psychology program. These placements allow a student to apply theoretical knowledge to develop and acquire the necessary skills to be a competent practitioner. Assessment of field placements to evaluate student performance is typically measured both during and on completion of each field placement. This evaluation process is completed by the placement supervisor to ensure the requirements of training are being met, to provide feedback to the student and the program coordinators, and make 
sure the level of skill achieved is to a satisfactory standard (Australian Psychology Accreditation Council, 2010; Kaslow, 2004; Kaslow et al., 2009).

It is common practice for placement supervisors to assess the progress of students on field placements using competency evaluation rating forms (CERFs; Kaslow, 2004). These forms are usually comprised of multiple items measuring different competency domains and are most often rated using Likert scales. They are generally easy to use, relatively cheap to administer, simple to score, and tend to be accepted as sufficient to measure both general and specific competencies (Gonsalvez et al., 2013; Kaslow et al., 2009). This is despite persistent concerns that CERFs do not adequately protect against halo or overly lenient ratings by supervisors (Gonsalvez et al., 2013).

Building on a three-dimensional competency model encompassing foundational and functional competencies progressing through stages of professional development originally proposed by Rodolfa et al (2005), the Benchmarks Work Group (Fouad et al., 2009) elaborated, extended, and offered a range of behavioural anchors for a competency framework. The framework describes three levels of professional development including, readiness for practicum work, readiness for internship, and readiness to enter practice. This version of the Competency Cube (Fouad et al., 2009) includes fifteen core competencies that include seven foundational competencies (e.g., professionalism, reflective practice, individual and cultural diversity) and eight functional competencies (e.g., assessment, intervention, teaching, research and evaluation). Whilst foundational competency domains represent "the building blocks of what psychologists do" (Rodolfa et al., p 350), functional represent broad domains of functioning and "describe the knowledge, skills, and values necessary to perform the work of a psychologist”, (p. 351). A range 
of competency-based initiatives have yielded valuable progress in the definition, delineation, classification, sequencing, and benchmarking of competencies (APA, Commission of Accreditation, 2015). These definitions also reveal how competency initiatives may be perceived differently by educators on the one hand and by regulators on the other (see Schaffer, Rodolfa, Hatcher, \& Fouad, 2013). Despite these "perspective" differences, in a broad sense, there has been a growing expert consensus on core competency domains and their essential elements. A key weakness is that the hypothesized dimensions, domains, and developmental stages upon which the competency edifice rests have received little empirical validation. A notable preliminary evaluation of competency ratings through hierarchical clustering techniques found that from a measurement perspective, several competency domains overlap substantially and are not all distinct or distinguishable (Gonsalvez et al., 2015). Further, whilst the entire range of 15 core competencies applies to professional psychology education and training, a narrower list of competencies apply to practicum and internship training of health service practitioners (American Psychological Association, Commission of Accreditation, 2015; Rodolfa et al., 2013).

It is widely accepted that there is a developmental trajectory that students take in acquiring competencies in various domains (Talmi et al., 2015). However, it is not clear at what rate students develop these different competencies nor how they develop and gain competencies during field placements.

To achieve the transformation from trainee to an independent practitioner, both student and supervisor work together to ensure the student develops the necessary professional skills across all competency domains. It has been argued that for students to progress "Supervisory interventions, as one might expect, should vary according to the developmental level of the trainee (for any given domain)” 
(Stoltenberg, 2008, p. 43). Although the experience of supervisors suggests that trainees’ competency development varies across domains, there is little empirical research supporting these anecdotal observations. Being able to accurately identify the specific developmental trajectory of an individual trainee and being able to also consider this in the context of the trajectories of other trainees provides multiple reference points for understanding a trainee’s progress and competence.

In the only published study we could locate that assessed multiple competencies of the same students over multiple time points, 57 clinical psychology students were asked to complete a self-assessed competency checklist at both entry and completion of their field placements (Larkin \& Morris, 2015). Completion of the competency checklist by students enabled them to identify both the competencies gained but also the self-perceived gaps that remained. Through this review process students needing more support were identified along with the areas where extra help was needed. The results revealed the rate of acquisition of different competencies was not equal across the different domains. Some competencies started at a higher level at entry to training (acquired before entering the program) than others and some were acquired more rapidly than others after training commenced. Many students felt on admission to the program that they possessed the foundational competencies such as professionalism, reflective practice, and relationships, with the exception of ethical and legal issues. This is perhaps not surprising since students may not have had practice based experiences of ethical or legal issues before commencing their program of study and the acquisition of this competency happened at a much slower rate. Competencies related to diversity issues also followed a slower rate of development and scientific knowledge based skills were acquired much quicker than skill based research competencies. Students tended to enter the course with low levels of many 
applied clinical competencies (e.g., assessment, intervention and consultation) but the acquisition of these skills is rapid in the first year and then levels off with relatively smaller gains made in subsequent years of training.

A limitation of the method used by Larkin and Morris (2015) was its reliance on student self-report. Although students can provide self-perceived ratings of competence, they may not be aware of the expected standards of competency established by professional programs, supervisors, or the profession more broadly. As a result it is possible they over or underrate their competencies in various domains. A further limitation was that ratings were only made once a year over a maximum of 5 years. Such infrequent ratings may mean that developmental changes that occur in a briefer window of time may be missed. Further, infrequent competency assessment means that opportunities to provide timely feedback that allows for remedial work are potentially lost. Regular assessment of student's competencies can clarify typical developmental trajectories in different competency domains, identifying students who are struggling to progress in particular domains, and allowing earlier and more targeted support. Data from regular assessments can potentially inform the development of training programs to better prepare and support student learning.

Gonsalvez et al. (2015) provide evidence that the acquisition of competency does not follow a steady stepwise progression to competency. Using supervisor ratings of health service psychology trainees at mid and end placements, the results from the assessments during a two-year period reported that learning in the early placements was greater followed by smaller and statistically insignificant increases in the latter placements. The authors also note that for some competencies more teaching may be required than for others (Gonsalvez et al., 2015). Therefore, the results from Gonsalvez et al. (2015) suggest that these skills may not increase in magnitude as 
suggested by the competency benchmarks. For example, some students potentially commence their training with strong interpersonal skills and may be naturally empathic. This could create a ceiling effect whereby these students' skills do not increase substantially (Williams \& Erickson Cornish, 2015). Analysis of developmental trajectories as a function of domains and the possibility that different domains might follow different developmental trajectories has implications for health service psychology programs (e.g. levels of training intensity).

Whilst evidence exists to support and quantify the core competencies needed to be attained to practice as a professional psychologist (Fouad et al., 2009; Kaslow \& Bell, 2008), a paucity of research has explored how competencies are attained during placements. Access to this information could assist programs to refine training, supervision and/or develop remediation experiences more efficiently. For example, if we know that competency in "Professional skills" and "Response to supervision" is attained relatively quickly by most students, but a student is still obtaining low ratings by the end of the first placement, we can intervene early. Understanding the trajectory of acquiring these competencies during field placements will not only identify students who are struggling with developing the necessary skills it will enable programs to focus more time on particular competencies that are harder to acquire.

The aim of the current research is to describe trainees' developmental trajectories across competency domains over multiple placements as assessed by placement supervisors. Further, we hypothesise that there will be significant differences in the competency ratings for different domains at the first placement. Specifically, we hypothesize that the rate of competency acquisition will occur significantly earlier for professional attitudinal domains (e.g., ethical and professional behaviours) compared to assessment and intervention domains. 


\section{Method}

\section{Participants}

Participants were clinical supervisors and psychology trainees enrolled in one of five participating universities providing clinical psychology training programs accredited by the Australian Psychology Accreditation Council (APAC) and the Clinical College of Australian Psychological Society (APS). There are 42 accredited Clinical Psychology training programs in Australia (APAC, 2017) and although the intake each year varies from program to program they typically fall in the range of 15 to 25 new trainees in each program each year. Trainees were enrolled in either a master's or doctoral program after completion of four years of full-time psychology training at the undergraduate level. The master's program is two years of full time study and doctoral programs are typically four year programs. The major difference between the master's and $\mathrm{PhD}$ programs is the requirement for a doctoral research thesis in the PhD programs. For Doctor of Clinical Psychology (DPsych) programs, there are also usually two further specialist taught subjects (e.g., Personality disorders), additional practicum hours and a more substantial doctoral thesis.

The data for the study comprised end-placement competency ratings obtained by 281 clinical psychology trainees rated by 238 supervisors during the 2012-2013 period. Of this initial data set, 147 supervisors (62\%) and 277 trainees (98\%) consented to submit their assessment data for research. Individuals who chose not to participate were excluded from the final data set, which consisted of competency ratings provided by 143 supervisors for 252 psychology trainees. As part of their clinical training, trainees complete three or more field placements during a two-year period. The initial placement was usually at the university's psychology clinic with 
subsequent placements occurring at external agencies. Each placement included between 200 and 300 placements hours, including a minimum of 80-100 hours of face-to-face client contact during each placement.

All supervisors satisfied academic and professional requirements for supervision mandated by the accrediting bodies. All supervisors were clinical psychologists who held the requisite qualifications (clinical psychology master's or doctoral degree from an accredited training institution), had the relevant postqualification clinical psychology experience to become eligible for full membership of the APS College of Clinical Psychologists, and had supervisor training that was approved by the Psychology Board of Australia.

Competency ratings were completed by placement supervisors at mid and end placement. Data were obtained from trainees assessed over two academic years, 2012 and 2013. Participant information concerning age and sex was not included for research purposes to ensure the anonymity of students (programs typically have a small intake with relatively small proportions of males [e.g., 17/126 (13.5\%) were males in one participating program over 7 consecutive years].

\section{Measure}

Clinical Psychology Practicum Competencies Rating Scale (CWPRS). The

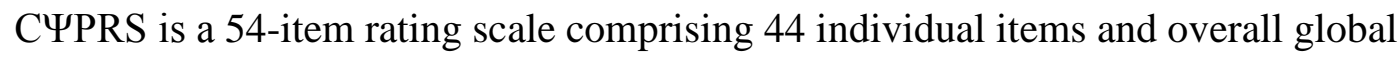
ratings for the 10 competency domains. Nine of the ten competency domains was included in the present analysis. Psychological Testing Competence was not included because in many placements supervisors indicated that this domain was not the focus of the placement and they provided "not applicable” ratings. Only the overall global ratings for nine competency domains are reported in the current study since these 
were replicated at both mid-placement and end-placement. The nine competency domains were: Counselling, Clinical Assessment, Case formulation, Interventions, Ethical attitude and behaviour, Scientist practitioner, Professional, Reflective practice, and Response to supervision. For each overall rating, the competency domain is named and has a brief descriptor as in the following examples: “Clinical Assessment Competencies - Overall Rating: Performs adequate assessments in a time efficient and in a personally/socio-culturally sensitive manner, appropriately prioritises issues, and assesses risk,” and "Ethical Attitude and Behaviour - Overall Rating: Demonstrates knowledge of ethical/professional codes, standards and guidelines, and commitment to their application. Maintains appropriate and respectful boundaries and seeks consultation on ethical issues.”

Ratings are made based on a four-stage developmental framework ranging from Beginner (Stage 1) through to Competent (Stage 4). Each item is rated on a 0-10 point visual analogue scale ranging from Beginner (0, Stage 1) to Competent (10, Stage 4), with intermediate, equidistant anchors being Stage 2 and Stage 3. Supervisors are provided with instructions to rate trainees in reference to a notional absolute standard of competent professional practice defined as comprising capabilities and skills on par with clinical psychologists working in their first job following completion of their master's degree.

The CYPRS was developed from earlier versions of similar scales used by the participating universities and the list of practicum competencies identified by Hatcher and Lassiter (2007). Because the CYPRS was designed to measure competency ratings at end of clinical psychology placements, it covers a narrower range of domains compared to those prescribed for broader professional training (e.g., Fouad et al, 2009), and excludes competencies mostly relevant to more experienced 
practitioners (e.g., consulting, supervision and advocacy). In an overall sense, the 10 domain structure of the CYPRS is representative of frameworks relevant to assessment of practicum and placement competencies for health practitioners (e.g., Hatcher \& Lassiter, 2007; Rodolfa et al., 2013). The only exception is that whilst cultural and diversity competencies often constitute an independent cluster in some frameworks (e.g., American Psychological Association, Commission on Accreditation. 2015; Rodolfa et al, 2013) these are incorporated within assessment and intervention competencies in the CYPRS (e.g., ability to undertake assessments in a socio-culturally sensitive manner, ability to integrate cultural knowledge into formulation).

\section{Procedure}

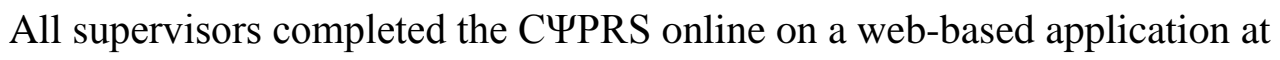
both the mid-placement and end-placement time points. The online format ensured that all supervisors completed the scale in a uniform sequence. At mid-placement, supervisors rated overall competence for each global domain. At end-placement, supervisors rated overall competence for a domain and then completed additional more specific sub-domain ratings. All items within a domain were completed before the next domain was presented. Supervisors and students provided informed consent for their de-identified data to be included in the research. The project was approved by the Human Research Ethics Committees of each of the participating universities.

\section{Data Analysis}

Although trainees could have more than four placements, most students completed four placements and it was relatively rare for more than four placements to be completed (9.52\%). Consequently, the focus of the analyses is on the first four 
placements. Each placement has a mid-placement rating and an end-placement rating. The following acronyms are used to designate the eight different time points: P1mid, P1end, P2mid, P2end, P3mid, P3end, P4mid, P4end. When data collection commenced, trainees in the programs were at different stages of their training. Thus, some could have had ratings completed for any one of the four different placements. As a result sample sizes vary between placements. Similarly, some may have had ratings completed for only one placement while others had ratings for two or more placements. The analyses were in three major parts.

The first focused on competency ratings for all participants across the four different placements. Descriptive data are reported. The second focused on those participants who had ratings for two consecutive ratings firstly within a placement (e.g. P1mid to P1end) and then between placements (e.g., P3end to P4mid). Pairedsamples t-tests were conducted to detect statistically significant differences in ratings.

The third part of the analysis focused on those participants who had all four ratings for two consecutive placements (e.g., P2mid-P2end-P3mid-P3end). In these analyses the total competency scores are used. General Linear Modelling for repeated measures (MANOVA) using SPSS-Version 21 was used to determine whether ratings increased significantly over time. Paired-sample t-tests were conducted to detect any statistically significant difference from one rating to the next.

\section{Results}

Of the 252 trainees, mid and end placement data for each of the four placements ranged from 76 to 116 (see Table 1).

\section{Competency Ratings for Each Domain for All Participants Across the Four}

\section{Placements}


Figure 1 provides the means for each domain across placements and shows a clear ascending stepped pattern from early to later placements. Within each placement, there is a consistent increase in competency for all domains. However, there is typically a slight decrease in the competency ratings at mid-placement for the subsequent placement (e.g., going from P1end-rating to P2mid-rating). The magnitude of this decrease appears to vary between competency domains. For example, Intervention competencies seem to have larger reductions between placements than do Ethical Attitude and Behaviour competencies. There also appears to be some variation in the starting point (P1mid ratings) across different competency domains. Initial P1mid-ratings for Intervention competencies and Case formulation are the lowest ( $M=6.37$ and $6.45 / 10$ respectively) and Response to supervision and Ethical Attitude and Behaviour the highest ( $M=7.80$ and 7.74/10 respectively). By P4end, the range across all domains is much narrower with a low of 9.54 for Scientist practitioner approach and a high of 9.82 for Ethical Attitude and Behaviour.

(Insert Figure 1)

\section{Within Subjects Comparisons for Mid- and End-placement within Placement}

Given that the data depicted in Figure 1 are across participants at each measurement point, there is also a need to verify these patterns within participants. Table 1 provides means for all paired mid- and end-placement ratings within each of the four placements. Within each placement all paired t-test comparisons between mid- and end-placement were significant for all competency domains $(\mathrm{p}<.001$, 2 tailed).

(Insert Table 1)

Within Subjects Comparisons for End- and Mid-placements between Placements 
Descriptively, there were decreases between end-ratings from one placement and mid-ratings for the next placement. There were far smaller numbers of matched (within subjects) ratings between end placement ratings and the next mid-placement rating (range $n=27$ to 40 ). Paired samples t-tests were conducted to test whether the decreases from a prior end-placement rating to the next mid-placement rating reached significance. Of the 27 comparisons only 5 were significant $(\mathrm{p}<.05$, 2-tailed) and four of these occurred from the P1end to P2mid. Specifically, there was a significant decrease for Assessment, $t(29)=2.58$; Case formulation, $t(26)=3.00$; Interventions, $t(27)=3.27$; and Scientist practitioner competencies , $t(29)=2.31$ between P1end and P2mid. There was also a significant decrease for Reflective Practice, $t(38)=2.21$ from P2end to P3mid.

\section{Total Competency Ratings Within Subjects for Total ratings across Two}

\section{Placements}

The following sequences for two placements were assessed, (A) 1mid-1end2mid-2end, (B) 2mid-2end-3mid-3end, and (C) 3mid-3end-4mid-4end. Samples sizes for each sequence ranged from 25 to 39.

For sequence (A) there was a significant effect for time, Wilks’ Lamba $=.33$, $F(3,22)=14.72, p<.001$, multivariate partial Eta squared $=.67$.

For sequence (B), there was a significant effect for time, Wilks’ Lamba $=.24$, $F(3,28)=30.42, p<.001$, multivariate partial Eta squared $=.77$.

For sequence (C) there was a significant effect for time, Wilks’ Lamba $=.20$, $F(3,36)=34.13, p<.001$, multivariate partial Eta squared $=.80$. 
Pairwise comparisons for all three ANOVAs revealed the same pattern for all three sequences. There was a significant increase within each placement (mid to end) but no significant difference between placements (end to mid).

\section{Discussion}

The results show a distinct ascending stepped pattern occurring across all competency domains from early to late placements. The starting point of the ratings varied across domains, with the ratings for some domains starting substantially lower than others. In addition, slight decreases in competency ratings were observed between the end-placement and subsequent mid-placement reviews, with notable variation in the magnitude of decrease for different domains. To our knowledge, this is the first study to demonstrate that the trajectory of competency development does not develop as a gradual ascending slope, but instead displays a see-sawing effect. However, the decrease in competency acquisition between the end of one placement and the start of the following placement was only significant for some domains and was largely restricted to the transition from Placement 1 to Placement 2 . In the current research context (and in Australia, generally) almost all first practicum placements occur in the university psychology training clinics where very close supervision can be provided as trainees develop their foundational skills. Clients of these clinics vary in the types and severity of problem presentations but programs attempt to initially allocate cases to beginning trainees that are relatively uncomplicated. In practice, this is not always achievable, but it is possible that on average the type and severity of problem presentations is different than they might encounter on subsequent placements. It is expected that trainees' subsequent placements are in adult psychiatric and child/adolescent treatment contexts. The decrease in competency ratings between placements may therefore accurately reflect less competence due to new and diverse 
clinical expectations and skills. These latter placements (P2, P3, P4) are more likely to be in public sector mental health services where presentations may be at the more severe end of the spectrum. In addition there are likely to be additional content areas that trainees need to learn, specific to these new placements and this seems to be particularly in the domains of Assessment, Case formulation and Interventions. There were almost no significant decreases in competencies between placements 2, 3 and 4 . This is consistent with prior research indicating that medical student's competencies during placements are not found to be affected by encountering different patients (Wimmers, Schmidt, \& Splinter, 2006). For clinical psychology training, at least in Australia, it appears there is a more consistent acquisition of competency across domains for placements later in a trainee’s candidature.

Some caution is needed in viewing lower competency ratings between placements as being seen as competencies "lost”. As noted, it is likely that this reflects new learning demands for a different clinical setting. Further, there may be slightly more demanding standards by field supervisors in these placements. Finally, caution is needed because the between placement analyses involved relatively small sample sizes in the paired comparisons.

Visually, the difference in the trajectories and stepped patterns between domains was most notable between the domains for Intervention and Ethical Attitude and Behaviour. It was hypothesised that the rate of competency acquisition would occur significantly earlier for professional attitudinal domains (e.g., ethical and professional behaviours) compared to assessment and intervention domains. Intervention had a pronounced ascending stepped pattern across all four placements, whereas for Ethical Attitude and Behaviour the pattern was flatter. More detailed analyses of the two domains demonstrated that they started at different levels of 
competency at the first mid-placement assessment. Further, the trajectory differences between these two domains are such that Ethical Attitude and Behaviour had a smoother ascending stepped pattern whereas Intervention tended to have more a more pronounced see-sawing pattern.

Overall, these results suggest that different competencies firstly start out at different levels, as suggested by Nash and Larkin (2012), and then have different trajectories. All competencies started at a relatively high level in both this study and Larkin and Morris' (2015) study, and this has been attributed to the robust and rigorous selection procedures for entry into clinical psychology programs. Further, it seems that competencies broadly in the foundational domain that include attitudinal and professional behaviours tend to transfer more readily between placements whereas those that might require specific knowledge to a different placement (e.g., intervention, case formulation) may require additional work to achieve a similar level of competency.

Larkin and Morris (2015) reported that different competencies were acquired at different rates than others. By way of example, competencies related to diversity were attained at slower rates than other competencies and this was thought due to their cohort of students not being exposed to an ethnically diverse client group until their internship. In another example, students may have no practical experience to develop assessment competencies until entering a graduate program and then undertake extensive coursework focusing on this competency during the first year. It is thought this pattern of experience contributed to the slope for the acquisition of this competency to be steep to begin with, and then display little change over the remaining years of the program (Larkin \& Morris, 2015). As not all competencies are attained at the same rate over a clinical psychology program, these results and ours 
provide support for considering a focus on training on certain competencies that students may not acquire as quickly as others (e.g., intervention competencies). It is also of note that in a previous study, Intervention and Ethical Attitude and Behaviour were exemplars of domains that congregated in two distinct clusters, namely Assessment and Intervention and Good Practitioner Attributes, respectively (Gonsalvez et al., 2015). It will be helpful to determine if the different developmental trajectories observed for these two domains represent trends that characterise the two clusters.

There is general agreement about what the core competencies are for a psychologist to practice, and agreement on the primary and foundational and functional competencies trainee should possess (Fouad et al., 2009; Rodolfa et al., 2005; 2013). The notion that the development of professional competency happens over a continuum of progressive competence is often applied (Fouad et al., 2009), but the exact trajectory of development across the domains has not previously been explored. Using data for mid- and end-placement it is not only possible to observe the trajectory of different competencies acquired over consecutive placements but to also clarify that some competencies are lower between the first and second placement in particular.

\section{Strengths and Limitations}

There has been considerable attention to the enumeration and description of the core competencies for psychology trainees, but there has been less attention to assessing the acquisition of these competencies. A strength of this study is having access to a large number of students’ placement assessments at both mid and end of placement, allowing student progress to be explored not only across placements but to 
track student progress within a placement. Previous evidence only relied on annual evaluations which were by student self-report (Larkin \& Morris, 2015).Without the mid-placement assessments, it would not be possible to observe the drop in competency between the end and the beginning of the consecutive placements.

A weakness of the study is that placement data were not available for each participant across all four placements and all eight-time points. With complete data, it would be possible to further explore the acquisition of competencies across the entire training program for each student. As such datasets grow there may also be the ability to clarify changes in the trajectory dependent on the content or type of placement experience (e.g., child/adolescent focus versus adult). Another limitation was that only two thirds of supervisors agreed to participate in the study. It is unclear why a third of supervisors did not agree to participate when we had $98 \%$ of trainees agree. It is possible that they were concerned about the reliability of their ratings being scrutinised or worried that participation may involve more demands on their time. Of greater concern, are factors that might be related to the trajectory or progress of students. For example, if supervisors who declined did so because their students were making less-than-satisfactory progress, then the mean values obtained may be inflated. Thus, some caution is warranted in generalising the results until great clarity around reasons for supervisors’ non-participation can be obtained.

Additionally, although the ratings are based on the student successfully developing actual behaviours, the assessment of whether competencies have been acquired is based on the subjectivity of the supervisor. This has the potential for the supervisor to provide ratings that may not accurately reflect student performance. Questions have been raised about the reliability and validity of trainees assessment

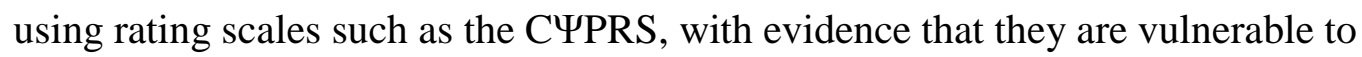


leniency and a halo bias (Bogo, Regehr, Hughes, Power, \& Globerman, 2002;

Gonsalvez \& Crowe, 2014; Gonsalvez \& Freestone, 2007). The general pattern of lower than expected mid-placement ratings combined with higher end-placement ratings could also be explained if the leniency bias was more pronounced at endplacement (when the ratings were of greater salience and of greater personal and professional consequence to the trainee) compared with ratings at mid-placement. Specifically, whilst lower end-placement ratings have implications for both the trainee and may also reflect badly on the supervisor, lower mid-placement ratings do not carry the same effects. The Competency Assessment Toolkit (Kaslow et al., 2009) suggests many different measures for assessing competency. These include recorded or live performances, simulated role play, consumer surveys, and objective structured clinical examinations along with the more traditional supervisory rating scales. Implementation of some of these tools for measuring acquisition of competency should be considered to improve and provide more confidence in the assessment of clinical psychology trainees.

\section{Implications}

An important implication of the current study is that competency domains may indeed have different developmental trajectories. Most competency models until now have tacitly assumed that the range of competency domains go through a similar number of stages (e.g., from novice to competence in four stages, in our model). The current study adds to the gradually growing evidence that this may not actually be the case. Results instead showed that domains varied in their starting points and in the magnitude of change across an overall ascending stepped progression.

Plotting the developmental trajectories of the different competency domains is critical to any endeavour that seeks to enhance the effectiveness of practitioner 
training. From this perspective, the current study makes a valuable contribution. The assessment process allows students to receive feedback on their progress and also to chart their strengths and weaknesses during placements, enabling the student and supervisor to focus on where they need to improve. These data have the potential to be used as a benchmark to indicate the expected level of competency required for students across each placement, thus enabling supervisors to identify students who are not reaching the benchmark for individual domains. The possibilities of being able to benchmark students’ progress to provide indicators of the level of competency expected across the domains at different time points has the potential to inform changes in course delivery. For example, if course delivery were to change from face-to-face- to online delivery. Having a benchmark of the level of competency acquired at given placements could provide course co-ordinators with an early indication whether changes to the course/program affect student learning outcomes. These data can also inform training programs about what domains are more likely to need more resources (e.g., Intervention competency). Evaluating student competencies allows for students who are struggling to be identified. This enables programs to develop remediation plans for individual students and to serve as effective gatekeepers for the profession when needed. 


\section{References}

American Psychological Association, Commission on Accreditation. 2015. Standards of Accreditation for Health Service Psychology. Retrieved from http://www.apa.org/ed/accreditation/about/policies/standards-ofaccreditation.pdf

Australian Psychology Accreditation Council. (2010). Rules for accreditation and accreditation standards for psychology courses. Melbourne: Author.

Australian Psychology Accreditation Council. (2017). Currently accredited psychology courses in Australasia. Retrieved from https://www.psychologycouncil.org.au/course-search/australia, 18th November 2017.

Bogo, M., Regehr, C., Hughes, J., Power, R., \& Globerman, J. (2002). Evaluating a measure of student field performance in direct service: Testing reliability and validity of explicit criteria. Journal of Social Work Education, 38(3), 385-401.

Fouad, N. A., Grus, C. L., Hatcher, R. L., Kaslow, N. J., Hutchings, P. S., Madson, M. B., . . Crossman, R. E. (2009). Competency benchmarks: A model for understanding and measuring competence in professional psychology across training levels. Training and Education in Professional Psychology, 3(4 Suppl. 1), S5-S26. doi:10.1037/a0015832

Gonsalvez, C. J., Bushnell, J., Blackman, R., Deane, F., Bliokas, V., Nicholson-Perry, K., . . . Knight, R. (2013). Assessment of psychology competencies in field placements: Standardized vignettes reduce rater bias. Training and Education in Professional Psychology, 7(2), 99-111. doi:10.1037/a0031617 
Gonsalvez, C. J., \& Crowe, T. P. (2014). Evaluation of psychology practitioner competence in clinical supervision. American Journal of Psychotherapy, 68(2), 177-193.

Gonsalvez, C. J., Deane, F. P., Blackman, R., Matthias, M., Knight, R., Nasstasia, Y., .. . Bliokas, V. (2015). The hierarchical clustering of clinical psychology practicum competencies: A multisite study of supervisor ratings. Clinical Psychology: Science and Practice, 22(4), 390-403. doi:10.1111/cpsp.12123

Gonsalvez, C. J., \& Freestone, J. (2007). Field supervisors' assessments of trainee performance: Are they reliable and valid? Australian Psychologist, 42(1), 2332. doi:10.1080/00050060600827615

Gonsalvez, C. J., \& Milne, D. L. (2010). Clinical supervisor training in Australia: A review of current problems and possible solutions. Australian Psychologist, 45(4), 233-242. doi:10.1080/00050067.2010.512612

Hatcher, R. L., \& Lassiter, K. D. (2007). Initial training in professional psychology: The practicum competencies outline. Training and Education in Professional Psychology, 1(1), 49-63. doi:10.1037/1931-3918.1.1.49

Kaslow, N. J. (2004). Competencies in professional psychology. American Psychologist, 59(8), 774-781. doi:10.1037/0003-066X.59.8.774

Kaslow, N. J., \& Bell, K. D. (2008). A competency-based approach to supervision. In C. A. Falender \& E. P. Sharfranske (Eds.), Casebook for clinical supervision: A competency-based approach (pp. 17-38). Washington, D. C.: American Psychological Association.

Kaslow, N. J., Grus, C. L., Campbell, L. F., Fouad, N. A., Hatcher, R. L., \& Rodolfa, E. R. (2009). Competency assessment toolkit for professional psychology. 
Training and Education in Professional Psychology, 3(4), S27-S45. doi:10.1037/a0015833

Kenkel, M. B., \& Peterson, R. L. (2009). Competency-based education for professional psychology. Washington, DC: American Psychological Association.

Larkin, K. T., \& Morris, T. L. (2015). The process of competency acquisition during doctoral training. Training and Education in Professional Psychology, 9(4), 300. doi:10.1037/tep0000091

Nash, J. M., \& Larkin, K. T. (2012). Geometric models of competency development in specialty areas of professional psychology. Training and Education in Professional Psychology, 6(1), 37. doi:10.1037/a0026964

Rodolfa, E., Bent, R., Eisman, E., Nelson, P., Rehm, L., \& Ritchie, P. (2005). A cube model for competency development: Implications for psychology educators and regulators. Professional Psychology: Research and Practice, 36(4), 347354. doi:10.1037/0735-7028.36.4.347

Rodolfa, E., Greenberg, S., Hunsley, J., Smith-Zoeller, M., Cox, D., Sammons, M., . . . Spivak, H. (2013). A competency model for the practice of psychology. Training and Education in Professional Psychology, 7(2), 71-83. doi:10.1037/a0032415

Roth, A. D., \& Pilling, S. (2008). A competence framework for the supervision of psychological therapies Retrieved from https://iris.ucl.ac.uk/research/browse/showpublication?pub_id=88611\&source_id=1 14 September 2012

Schaffer, J. B., Rodolfa, E. B., Hatcher, R. L. \& Fouad, N. A. (2013). Professional psychology competency initiatives: Reflections, contrasts, and 
recommendations. Training and Education in Professional Psychology, 7(2), 92-98. doi: 10.1027/a0032038

Smith, A. J., Kleun, W. C., \& Hutschemaekers, G. J. (2007). Therapist reactions in self-experienced difficult situations: An exploration. Counselling \& Psychotherapy Research, 7(1), pp. doi:10.1080/14733140601140865

Stoltenberg, C. D. (2008). Developmental approaches to supervision. In C. A. Falender \& E. P. Shafranske (Eds.), Casebook for clinical supervision: A competency-based approach. Washington, DC: American Psychological Association.

Talmi, A., Lovell, J. L., Herbst, R. B., Margolis, K. L., Muther, E. F., \& Buchholz, M. (2015). Postdoctoral fellows’ developmental trajectories in becoming pediatric primary care psychologists. Clinical Practice in Pediatric Psychology, 3(3), 233. doi:10.1037/cpp0000100

Williams, J. D., \& Erickson Cornish, J. A. (2015). Responding to Clinical Psychology Practicum Competencies: An APPIC Perspective. Clinical Psychology: Science and Practice, 22(4), 410-413. doi:10.1111/cpsp.12127

Wimmers, P. F., Schmidt, H. G., \& Splinter, T. A. (2006). Influence of clerkship experiences on clinical competence. Medical Education, 40(5), 450-458. doi:10.1111/j.1365-2929.2006.02447.x 


\section{Figure Legends}

Figure 1. Mean competency scores for each domain across placements ( $n=76-$ 116). 
Table 1. Means and standard deviations for mid and end placements within each placement for all competencies

\begin{tabular}{|c|c|c|c|c|c|c|c|c|c|c|c|c|c|c|c|c|c|c|c|c|}
\hline \multirow[b]{3}{*}{ Competency } & \multicolumn{5}{|c|}{ Placement 1} & \multicolumn{5}{|c|}{ Placement 2} & \multicolumn{5}{|c|}{ Placement 3} & \multicolumn{5}{|c|}{ Placement 4} \\
\hline & \multicolumn{2}{|c|}{ Mid } & \multicolumn{2}{|c|}{ End } & \multirow[b]{2}{*}{$\mathrm{n}$} & \multicolumn{2}{|c|}{ Mid } & \multicolumn{2}{|c|}{ End } & \multirow[b]{2}{*}{$\mathrm{n}$} & \multicolumn{2}{|c|}{ Mid } & \multicolumn{2}{|c|}{ End } & \multirow[b]{2}{*}{$\mathrm{n}$} & \multicolumn{2}{|c|}{ Mid } & \multicolumn{2}{|c|}{ End } & \multirow[b]{2}{*}{$\mathrm{n}$} \\
\hline & M & SD & M & SD & & M & SD & M & SD & & M & SD & M & SD & & M & SD & M & SD & \\
\hline Counselling & 6.99 & 1.45 & 8.29 & 1.15 & 77 & 7.96 & 1.43 & 8.71 & 1.32 & 93 & 8.54 & 1.25 & 9.31 & 0.97 & 116 & 8.98 & 1.27 & 9.70 & 0.65 & 96 \\
\hline $\begin{array}{l}\text { Clinical } \\
\text { Assessment }\end{array}$ & 6.59 & 1.40 & 8.07 & 1.08 & 77 & 7.23 & 1.51 & 8.27 & 1.28 & 93 & 7.86 & 1.38 & 9.02 & 1.15 & 116 & 8.50 & 1.45 & 9.55 & 0.87 & 96 \\
\hline $\begin{array}{l}\text { Case } \\
\text { formulation }\end{array}$ & 6.45 & 1.54 & 8.04 & 1.17 & 76 & 7.12 & 1.52 & 8.33 & 1.49 & 88 & 7.87 & 1.38 & 9.06 & 1.12 & 107 & 8.71 & 1.30 & 9.60 & 0.69 & 88 \\
\hline Interventions & 6.37 & 1.55 & 7.95 & 1.08 & 76 & 7.27 & 1.29 & 8.31 & 1.20 & 86 & 7.93 & 1.40 & 9.00 & 1.13 & 107 & 8.65 & 1.38 & 9.58 & 0.64 & 91 \\
\hline $\begin{array}{l}\text { Ethical } \\
\text { attitude }\end{array}$ & 7.74 & 1.56 & 8.72 & 1.11 & 77 & 8.53 & 1.41 & 9.11 & 1.14 & 93 & 9.19 & 1.09 & 9.69 & 0.59 & 116 & 9.38 & 0.94 & 9.82 & 0.51 & 96 \\
\hline $\begin{array}{l}\text { Scientist } \\
\text { practitioner }\end{array}$ & 7.01 & 1.41 & 8.26 & 1.16 & 77 & 7.80 & 1.54 & 8.54 & 1.50 & 93 & 8.42 & 1.27 & 9.29 & 0.94 & 116 & 8.80 & 1.44 & 9.54 & 0.76 & 96 \\
\hline Professional & 7.61 & 1.63 & 8.61 & 1.14 & 77 & 8.54 & 1.57 & 9.06 & 1.29 & 93 & 8.92 & 1.31 & 9.48 & 0.85 & 116 & 9.35 & 0.95 & 9.74 & 0.52 & 96 \\
\hline $\begin{array}{l}\text { Reflective } \\
\text { practice }\end{array}$ & 7.44 & 1.62 & 8.42 & 1.09 & 77 & 8.00 & 1.33 & 8.88 & 1.18 & 93 & 8.44 & 1.46 & 9.32 & 0.96 & 116 & 8.96 & 1.24 & 9.58 & 0.71 & 96 \\
\hline $\begin{array}{l}\text { Response to } \\
\text { supervision }\end{array}$ & 7.80 & 1.62 & 8.80 & 1.08 & 77 & 8.45 & 1.37 & 9.15 & 1.06 & 93 & 8.91 & 1.15 & 9.53 & 0.78 & 116 & 9.31 & 0.99 & 9.68 & 0.73 & 96 \\
\hline
\end{tabular}

Note. All paired t-tests between Mid and End for all competencies and all placements were significant at $\mathrm{p}<.001$, 2-tailed. 